\title{
Peritoneoscopy in the Management of Catheter Malfunction During Continuous Ambulatory Peritoneal Dialysis
}

\author{
JOANNE A.P. WILSON, MD, and RICHARD D. SWARTZ
}

\begin{abstract}
Continuous ambulatory peritoneal dialysis is widely used in the maintenance of patients with chronic renal failure. Obstruction or displacement of the chronic dialysis catheter, which prevents dialysate drainage, can compromise ongoing dialysis. Conservative approaches (body position change, saline infusion, and enema) are often unsuccessful and more aggressive therapy may be required. We report the use of peritoneoscopy to reposition malfunctioning peritoneal dialysis catheters. The procedure proved to be safe and gave excellent long-term results.
\end{abstract}

Continuous ambulatory peritoneal dialysis (CAPD) has been widely used in the maintenance of patients with chronic renal failure since the description of the technique in $1976(1,2)$. Success of this treatment, however, is dependent upon good function of the peritoneal catheter. Some complications such as peritonitis, dialysate leakage, and exit site infection do not prevent continuing dialysis $(2,3)$. However, obstruction or displacement of the chronic catheter prevents dialysate drainage and limits ongoing CAPD $(3,4)$. Conservative approaches to drainage failure, which include body position change, saline infusion, and enemas, are often employed but are frequently unsuccessful (3). Often more aggressive therapy must be employed when conservative approaches fail: trocar manipulation (4), surgical repositioning (5), or replacement of the catheter (5). We report here an alternative approach. Peritoneos-

Manuscript received June 28, 1984; accepted October 10, 1984.

From the Division of Gastroenterology and Division of Nephrology, Department of Internal Medicine, University of Michigan Medical Center, Ann Arbor, Michigan 48109.

Address for reprint requests: Dr. Joanne A.P. Wilson, D-2107 Medical Professional Bldg., University of Michigan, Ann Arbor, Michigan 48109. copy with direct catheter manipulation was used with excellent long-term results to successfully correct malfunction of peritoneal dialysis catheters.

\section{MATERIALS AND METHODS}

Double-cuff chronic peritoneal dialysis catheters were originally placed under local anesthesia at the bedside by the technique of Tenckhoff $(6,7)$. At the time of catheter malfunction, peritoneoscopy was performed under local anesthesia in the standard fashion using a $10-\mathrm{mm}$ operating laparoscope (R. Wolf Medical Instruments). Blunt jaw grasping forceps were used for catheter manipulation.

Case 1. JS, a 41-year-old man with a history of chronic renal failure secondary to focal glomerulosclerosis, had been maintained on CAPD for two years. The patient had a history of a cadaveric kidney transplant approximately nine months earlier which had been rejected after one month. He presented to the renal clinic complaining of poor drainage from his dialysis catheter for several weeks. Infusion with 2 liters of $4.25 \%$ Dianeal $^{\circledR}$ was accomplished without difficulty; however, drainage was associated with a feeling of residual fluid and progressive weight gain. He had no previous problems with his CAPD and no history of peritonitis. X-ray of the abdomen revealed a posterior malposition of the catheter with shortening of the catheter in the anterior-posterior view. He denied fever, chills, and abdominal pain. Physical examination was remarkable for a well-healed surgical scar on the right lower abdomen. Laboratory studies 
were remarkable for a normal white blood cell count and electrolytes, anemia, blood urea nitrogen of $102 \mathrm{mg} / 100$ $\mathrm{ml}$, and creatinine $23.5 \mathrm{mg} / 100 \mathrm{ml}$. Bleeding time was normal.

Peritoneoscopy was performed under local anesthesia with morphine sulfate-diazepam sedation. A small incision was made in the left periumbilical area and the peritoneoscopic investigation executed with nitrous oxide pneumoperitoneum. The catheter was noted to be lodged posteriorly in the mesentery. Manipulating forceps were passed through the peritoneoscope, and the catheter was lifted to the anterior abdomen. No adhesions, resistance, or bleeding was noted. The procedure was terminated and free flow of dialysate was noted. The patient tolerated the procedure well with no significant symptoms. He was discharged on the day after the procedure. The patient subsequently noted good dialysate return which has continued for five months.

Case 2. JM, a 29-year-old man with chronic renal failure and maintained on CAPD, presented with poor dialysate return and bloody effluent. He had a history of chronic renal failure secondary to focal glomerulosclerosis, and CAPD was instituted six months prior to this event. He had no previous problem and was maintained on four 2 liter exchanges of $1.5 \%$ and $4.25 \%$ Dianeal. One day prior to admission the patient noted bright red blood in his Tenckhoff catheter; he was unable to drain dialysate, although fluid would flow in. In the clinic, similar findings were noted. Enemas and catheter infusion were unsuccessful. The patient denied fever, chills, or abdominal pain. He did admit to heavy lifting on the day of the event. Physical examination was remarkable for the absence of fever, abdominal tenderness, or mass. Peripheral edema was noted. Laboratory studies were remarkable for a hematocrit of $24 \%$, white blood cell count of $4700 / \mathrm{mm}^{3}$, normal electrolytes, blood urea nitrogen 114 $\mathrm{mg} / 100 \mathrm{ml}$, and creatinine of 24 . Dialysate analysis revealed 130,000 red blood cells and 310 white blood cells; culture was negative. An abdominal x-ray showed the catheter entering the right abdomen but malpositioned in the left lower quandrant posteriorly.

Peritoneoscopy was performed under local anesthesia and morphine sulfate-diazepam sedation. After nitrous oxide pneumoperitoneum, the peritoneoscope was passed into the peritoneum with the finding of serosanguineous fluid. The abdominal cavity was generally free of adhesions, although scarring was noted at a previous transplant site. The catheter was found firmly attached to the mesentery in the left lower quadrant. The catheter was manipulated free of adhesions by a grasping forceps passed through a second puncture site in the lower abdomen. A long column of adhesive tissue was noted attached to the catheter. After manipulation, free fluid drainage was noted. The forceps and peritoneoscope were withdrawn. The patient tolerated the procedure well with only minor abdominal discomfort. Peritoneal dialysis was continued with antibiotic instillation. The dialysate cleared over the next $8 \mathrm{hr}$ and the patient was discharged one day after the procedure. His creatinine decreased to $18.0 \mathrm{mg} / 100 \mathrm{ml}$, blood urea nitrogen to 90 $\mathrm{mg} / 100 \mathrm{ml}$, and he has had good catheter function for the ensuing six months.

\section{DISCUSSION}

The cases presented here represent the most common causes of catheter dysfunction-malposition with obstruction by mesentery and obstruction by adhesions (4). These complications are reported to occur in about $60 \%$ of catheters in the study by Davis et al (4); however, in our experience less than $10 \%$ of all chronic CAPD patients have these complications (8). Both of our cases occurred in patients with chronic well-functioning catheters which had been in place for more than six months. Conservative management of this problem (body position changes, saline infusion, and enema) has been recommended; however, studies would indicate that these measures may be successful in only about $25 \%$ of cases (3). These maneuvers were unsuccessful in our two patients. The use of trocar insertion and manipulation of the catheter has been reported effective (4), but such manipulation is a blind procedure and may require repeated insertions to restore free flow.

The use of direct examination of the catheter through the peritoneoscope allows accurate visualization of the cause of catheter malfunction and associated peritoneal disease as well as the results of the manipulation process at the time of the procedure. Since the bowel is visualized, trauma can be avoided. Any bleeding from adhesions can be dealt with immediately (9). Peritoneoscopy was performed in our patients without complication or undue discomfort. Long-term catheter function was restored.

Peritoneoscopy has been used in patients with chronic renal failure and peritoneal dialysis. These have included the evaluation of nephrogenic ascites (10), the initial placement of peritoneal dialysis catheters under direct visualization with the needle peritoneoscopy (11), and the evaluation of peritonitis in patients on CAPD (12). Peritoneoscopy was performed in these patients without any complications. One consideration in the patient on chronic peritoneal dialysis is the presence of peritoneal adhesions complicating peritoneoscope insertion. However, the use of peritoneal insufflation study (13), the absence of pain with infusion, and the absence of a previous history of peritonitis diminishes the possibility of adhesions as a complicating factor. Another relative contraindication to peritoneoscopy has been previous abdominal surgery. However, studies (14) would indicate that peritoneoscopy can be done safely and effectively in the 
presence of abdominal scars. This is especially possible when infraumbilical scars are present, as was noted in case 1 .

This report offers peritoneoscopy as an alternative approach to the management of chronic peritoneal dialysis catheter malfunction when conservative measures fail to restore function.

\section{REFERENCES}

1. Popovich RP, Moncrief JW, Deherd JB, Boman JB, Pyle WK: The definition of a novel portable/wearable equilibrium peritoneal dialysis technique. Abstr Am Soc Artif Intern Organs 5:64, 1976

2. Popovich RP, Moncrief JW, Nolph KD, Ghods AJ, Gwardowski J, Pyle WK: Chronic ambulatory peritoneal dialysis. Ann Intern Med 88:449-456, 1978

3. Ruben J, Adair CM, Raju S, Bower JD: The Tenckhoff catheter for peritoneal dialysis-an appraisal. Nephron 32:370-374, 1982

4. Davis R, Young J, Diamond D, Bourke E: Management of chronic peritoneal catheter malfunction. Am J Nephrol 2:8590,1982

5. Tenckhoff H: Chronic Peritoneal Dialysis: A Manual for
Patients, Dialysis Personnel and Physicians. University of Washington School of Medicine, Seattle, 1974, pp 49-50

6. Tenckhoff H: Chronic Peritoneal Dialysis: A Manual for Patients, Dialysis Personnel and Physicians. University of Washington School of Medicine, Seattle, 1974, pp 23-32

7. Tenckhoff H, Schechter H: A bacteriologically safe peritoneal access device. Trans Am Soc Artif Intern Organs 14:181-187, 1968

8. Swartz RD: Chronic Peritoneal Dialysis: Mechanical and Infectious Complications. Nephron 1984 (in press)

9. Trujillo NP: Peritoneoscopy and guided biopsy in the diagnosis of intraabdominal disease. Gastroenterology 71:10831085,1976

10. Ash SR, Wolf GC, Block R: Placement of the Tenckhoff peritoneal dialysis catheter under peritoneoscopic visualization. Dial Transplant 10:383-386, 1981

11. Craig R, Sparberg M, Ivanovich P, Rice L, Dordal E: Nephrogenic ascites. Arch Intern Med 134:276-279, 1974

12. Cunningham JT, Tucker CT: Peritoneoscopy in chronic peritoneal dialysis: Use in evaluation and management of complications. Gastrointest Endosc 29:47-50, 1983

13. Tucker CT, Cunningham JT, Nichols AM, Greer CI, Bailey GT: Cannulography with peritoneal air contrast study. Contemp Dial 3:9-16, 1982

14. Marti-Vicente A, Rodriguez JV, Alcala FM: Peritoneoscopy examination following abdominal operations. Gastrointest Endosc 25:144-145, 1979 